\title{
Arbor
}

\section{Cristianismo y comunidades: La construcción de la utopía}

\section{Pablo Augusto Guerra Aragone}

Arbor CLXV, 652 (Abril 2000), 671-000 pp.

El objetivo que perseguimos al escribir este artículo, es demostrar cómo desde el cristianismo hubo siempre intentos por construir experiencias concretas de carácter comunitario, y cómo estas tuvieron como proyecto realizable y posible, o sea como utopía, las formas de vida de las primeras comunidades cristianas que describen los Hechos de los Apóstoles. Es especialmente interesante en ese sentido, analizar la raiz profundamente crítica a lo culturalmente predominante por parte de las diferentes experiencias comunitarias. Nuestra lectura será entonces desde las ciencias sociales, y más concretamente de lo que hemos definido en otra oportunidad como una visión socioeconómica-solidaria.

\section{Las diferentes lecturas de lo comunitario}

Cuando empezamos a estudiar el fenómeno de las comunidades religiosas, nos encontramos con usos diferentes de lo comunitario, según el contexto de nuestro objeto de estudio. Es así que entiendo pertinente marcar una distinción de acuerdo al tipo de mirada que hacemos desde las ciencias sociales, que a su vez es diferente al uso que se le da desde una lectura teológica ${ }^{1}$. En el primer caso, las ciencias sociales hacen referencia a lo comunitario al menos desde dos puntos de vista muy distintos que llamaremos en esta ocasión, puntos de vista macro y micro social.

El concepto de lo comunitario desde el punto de vista macro social ha tenido un amplio uso en el campo de las ciencias sociales, que llega has- 
ta nuestros tiempos ${ }^{2}$, y como no corresponde hacer una arqueología del término, preferimos mencionar la visión que acerca del fenómeno tenían dos clásicos de la sociología, Weber y Tönnies, para luego analizar sus repercusiones contemporáneas.

En ambos clásicos, el concepto de comunidad surge como contrapartida del fenómeno más contemporáneo, racionalista y contractual que definían como sociedad. Dice Weber:

«Llamamos comunidad a una relación social cuando y en la medida en que la actitud en la acción social -en el caso particular, por término medio o en el tipo puro- se inspira en el sentimiento subjetivo (afectivo o tradicional) de los partícipes de constituir un todo.

Llamamos sociedad a una relación social cuando y en la medida en que la actitud en la acción social se inspira en una comprensión de intereses por motivos racionales (de fines o valores) o también en una unión de intereses con igual motivación» ${ }^{3}$.

A continuación, precisa los tipos más puros en las relaciones de comunidad y sociedad. De esta forma, los tipos más puros de sociedad son:

«a) el cambio estrictamente racional con arreglo a fines y libremente pactado en el mercado. Un compromiso real entre interesados contrapuestos que, sin embargo, se complementan; b) la unión libremente pactada y puramente dirigidas por determinados fines (Zweckverein), es decir, un acuerdo sobre una acción permanente, orientada en sus propósitos y medios por la persecución de los intereses objetivos (económicos u otros) de los miembros partícipes en ese acuerdo; c) la unión racionalmente motivada de los que comulgan en una misma creencia (gessinungsverein): la secta racional, en la medida en que prescinde del fomento de intereses emotivos y afectivos, y sólo quiere estar al servicio de la "tarea» objetiva (lo que ciertamente, en su tipo puro, ocurre sólo en casos muy especiales)». A diferencia de los diferentes tipos de comunidades, una de las características fundamentales de la actividad societaria racional es que tiene su escenario de socialización en el mercado ${ }^{4}$.

La comunidad, en tanto, expresa para Weber, fundamentos afectivos, emotivos y tradicionales. Es el caso de una cofradía religiosa, de una relación erótica, o incluso de una tropa unida por lazos de camaradería. La comunidad familiar, es sin embargo, quien mejor representa estas relaciones. Weber expresa, además, que las relaciones comunitarias, que dan lugar a valores afectivos, tiene lugar incluso entre las relaciones sociales. Lo inverso también es cierto, lo que - fiel a todo el pensamiento 
Weberiano- da lugar a conceptos muy amplios que abarcan una inmensidad de posibles situaciones. Aún así, Weber luego señala que «la comunidad es normalmente por su sentido la contraposición radical de la lucha... por otro lado, las sociedades son con frecuencia únicamente meros compromisos entre intereses en pugna...». Notemos, a manera de crítica inicial, cómo más allá de las contribuciones notorias en la materia, esta tipología es de difícil aplicación para aquellas actividades económicas que se realizan con vínculos comunitarios, lo que lleva claramente también en este clásico, nuevamente al predominio del mercado de intercambios como paradigma y sistema que subsume las relaciones de tipo solidario.

Por su lado, en el año 1919, el sociólogo alemán Ferdinand Tönnies publica su obra máxima, "Gemeinschaft und Gesellschaft», de notable parecido en cuánto estilo literario, a los textos de su compatriota Max Weber. En su Introducción, luego de definir el objeto de estudio de su obra (las relaciones recíprocas), comienza a definir los términos que entendemos fundamentales en la historia del pensamiento sociológico, y particularmente importantes para nuestro objeto de estudio. Es así que señala:

«la relación misma, y también la unión, se concibe, bien como vida real y orgánica - y entonces es esencia de la comunidad-, bien como formación ideal y mecánica- y entonces es el concepto de sociedad» ${ }^{5}$.

Estos términos, señala luego el autor, presentan evidentes contradicciones. En ese sentido, señala que:

«toda vida en conjunto, íntima, interior y exclusiva, deberá ser entendida, a nuestro parecer, como vida en comunidad. La sociedad es lo público, el mundo. Uno se encuentra en comunidad con los suyos desde el nacimiento, con todos los bienes y males a ello anejos. Se entra en sociedad como en lo extraño».

Los argumentos se suceden. Así, la vida en el campo sintetizará para Tönnies la vida comunitaria, más viva, auténtica y duradera. La sociedad, por su lado, producto de la cultura urbana de principios de siglo, se presenta como una vida pasajera y aparente.

El primer capítulo de su obra, es titulado «Teoría de la Comunidad». Desarrolla allí las características de esta organización societaria, enraizada fundamentalmente en relaciones de carácter familiar. No obstante ello, distingue tres especies originarias de comunidad: de parentesco, de vecindad y de amistad. En todos estos casos está presente el concep- 
to de «consenso", entendido como la inclinación recíproca-común, unitiva, en cuanto voluntad propia de una comunidad. Es, de otra manera, la «fuerza y simpatía social especial que mantiene unidos a los hombres como miembros del conjunto». De esta forma, el consenso se plasma en las relaciones comunitarias como un acuerdo tácito acerca de los deberes y facultades de cada uno, de lo considerado bueno y malo, etc. De suerte que este tipo de relaciones no está fundado en los contratos, sino en el consenso. Notemos cómo Tönnies ya está identificando las diferencias notorias en el plano social que introdujo la lógica mercantil capitalista. Citando investigaciones contemporáneas a su obra, se refiere al régimen agrario hindú, donde se señala que los precios están sujetos a una tasa tradicional de la que no se podían apartar; lo que indica la sujeción de lo económico a los intereses sociales, tal como luego insistiría Polanyi.

Estos clásicos darían pié algunas décadas después a la irrupción en las ciencias sociales de corrientes que insistirían en la necesidad de profundizar los mecanismos comunitarios por sobre los individualistas. En el plano de la historia de las ideas, este fín de siglo muestra en tal sentido un interesante debate académico entre liberales y comunitaristas; y justamente desde la Communitarian Network, fundada por el sociólogo Etzioni, surge un concepto diferente de lo comunitario que también conviene señalar, aunque más no sea brevemente.

En su The Moral Dimension: Towards a New Economics ${ }^{6}$, de 1988, Etzioni desarrolla un complejo concepto de lo comunitario, siempre en el plano que hemos llamado macro social, que nos aproxima más bien a una entidad orgánica, a un «nosotros» de normas, valores y principios, que funcionaría como soporte privilegiado de toda acción individual. El individuo, de esta manera, depende relacionalmente de su medio, pero a diferencia de las concepciones totalitarias, existe una especie de tolerancia social, de donde emerge la importancia de lo consensual no solo en materia de derechos, sino también de deberes. En su último libro en la materia y continuando en esta línea, señalaría que el paradigma de lo comunitario implica entonces una delicada combinación de orden social y autonomía ${ }^{7}$. Los comunitaristas, de esta manera, se separan radicalmente de la concepción liberal acerca de los vínculos entre individuo y sociedad; existiendo de esta manera un notable acercamiento teórico con ideas que tuvieron mucha influencia en los ambientes católicos (aunque también entre los cristianos en general) europeos y latinoamericanos en los años de postguerra: nos referimos a las contribuciones fundamentalmente, entre otros, de Mounier y Maritain ${ }^{8}$. 
Cristianismo y comunidades: La construcción de la utopía

Mounier, por ejemplo, sentenciaba en su Manifeste au Service du Personalisme de 1936, que el liberalismo había impuesto la visión de

«un individuo abstracto, buen salvaje pacífico y paseante solitario, sin pasado, sin futuro, sin vínculos, sin carne, provisto de una libertad sin norte, ineficaz juguete embarazoso con el que no se debe dañar al vecino y que no se sabe como emplear si no es para rodearse de una red de reivindicaciones que le inmovilizan con mayor seguridad aún en su aislamiento. En tal mundo, las sociedades no son más que individuos agigantados, igualmente replegados sobre sí mismos, que encierran al individuo en un nuevo egoísmo y le consolidan en su suficiencia.... ${ }^{9}$.

En el plano propositivo, y luego de repasar el valor de la Persona y los vínculos del yo-nosotros que retomaría luego Etzioni, comprueba la imposibilidad de fundar la comunidad esquivando la persona, de donde surge su concepto de comunidad personalista, o dicho de otra manera, una persona de personas.

En íntima conexión con los planteos de los modernos comunitaristas continuaba señalando:

«Si fuese preciso dibujar su utopía, describiríamos a una comunidad en la que cada persona se realizaría en la totalidad de una vocación continua fecunda, y la comunión del conjunto sería una resultante viva de estos logros particulares. El lugar de cada uno sería, en ella, insustituible, al mismo tiempo que armonioso con el todo. El amor sería su vinculo primero, y no ninguna coacción, ningún interés económico o vital, ningún mecanismo extrínseco. Cada persona encontraría allí, en los valores comunes, trascendentes al lugar y al tiempo particular de cada uno, el vínculo que los religaría a todos» ${ }^{10}$.

Maritain, por su lado, llega al concepto de comunidad luego de distinguir filosóficamente el individuo de la persona, y de señalar que «por naturaleza» la persona exige vivir en sociedad. Pero, lo importante y sustancial de su análisis es que el fin de esta sociedad no es el bien individual, sino el bien común; distanciándose por tanto de la visión individualista que destruye la sociedad, y de la totalitaria que destruye la dimensión personalista. Llegamos entonces a una conceptualización de lo comunitario como aquello relacionado al bien común, en el marco de un «humanismo integral».

En América Latina, uno de los discípulos más reconocidos de éstos autores ha sido sin duda el arquitecto y sociólogo uruguayo, Juan Pablo Terra. En su clásico libro «Mística, Desarrollo y Revolución» de 1969, basa 
su análisis propositivo, pleno de humanismo cristiano, en dos grandes pilares: el ideal democrático y el ideal comunitario. Este último, consiste fundamentalmente «en la idea de convivir compartiendo, por una consciente aceptación fraternal. Ese convivir y compartir, supone poner en común los derechos sobre muchas cosas, manejar, administrar, usar y gozar muchas cosas fraternalmente, sin tuyo ni mío» ${ }^{11}$. Recalca luego, que lo comunitario es básicamente un modo de relación entre personas, más que de relaciones con las cosas, en alusión al fenómeno muy discutido en la década del sesenta sobre la propiedad, que en este caso prefiere el autor manejar sin dogmas, admitiendo la necesidad de una pluralidad de combinaciones posibles.

De manera que lo que comparten estos autores al hacer mención a lo comunitario es una mirada «macro social» en el entendido que privilegian el conjunto de los atributos sociales, dirigiendo sus miradas a un proyecto de cambio más general («Sociedad Comunitaria» vs. «Sociedad Individualista», etc), ya sea de connotaciones conservadoras («vuelta al pasado», como sugiere por momentos Tönnies), ya sea de corte progresista, como claramente se presenta en los autores contemporáneos citados.

Una segunda lectura de lo comunitario que nos servirá para entender el impacto de estas ideas en las prácticas religiosas, es la que se puede hacer desde una mirada más micro sociológica: nos referimos a la mirada privilegiada por las categorías de análisis de la socio-economía solidaria. Aquí lo comunitario adquiere nuevas características, entre las cuáles no se pueden dejar de lado las económicas. En tal sentido consideraremos técnicamente comunidad, a aquella unidad económica, que posee, gestiona, produce, distribuye, consume y acumula, de acuerdo a una lógica y racionalidad alternativa, donde lo común predomina sobre lo individual. Desde este punto de vista, las comunidades se constituyen en objeto preferencial para estudiar las economías alternativas, pues representan las experiencias de mayor radicalidad antimercantilistas (entendiendo al mercado en este caso, solo como el mercado hegemónico de intercambios, donde predomina la lógica del homo oeconomicus).

A diferencia de la lectura sociológica anterior, de carácter más macro social, ahora estamos en presencia de una lectura micro que incluye los ingredientes también microeconómicos. Desde este punto de vista no tiene sentido hablar de «sociedad comunitaria», sino más bien de «experiencias comunitarias» en lo social y económico ${ }^{12}$. De alguna manera, esta nueva lectura es heredera de la anterior, pues las numerosas experiencias contemporáneas de comunidades suelen tomar en consideración el 
debate sociedad - comunidad; y liberalismo - comunitarismo. Es nuestra hipótesis además, que estas comunidades, organizadas y gestionadas de acuerdo a nuevos parámetros socioeconómicos, donde lo solidario se vuelve central, deben su éxito a un marco doctrinario especialmente fuerte que les da consistencia y fundamentalmente legitima lazos, valores y relaciones que en la cultura hegemónica son considerados anormales cuando no ridículos. En el caso de las comunidades religiosas, ese marco está dado por los idearios religiosos, de mayor perdurabilidad que los no religiosos, según se comprueba en el siguiente inventario de aproximadamente 250 experiencias comunitarias desde mediados del S. XIX a mediados del presente siglo ${ }^{13}$ :

\begin{tabular}{|c|c|c|}
\hline Sistemas & De base religiosa & De base no religiosa \\
\hline Sobrevivientes al cabo de un año & $90 \%$ & $50 \%$ \\
\hline Sobrevivientes al cabo de 25 años & $50 \%$ & $3 \%$ \\
\hline Sobrevivientes al cabo de 100 años & Varios & Ninguno \\
\hline
\end{tabular}

Fuente: J. Williams y E. Deets; citado por Desroche, H. Op. Cit.

En el primer mundo, esta lectura de lo comunitario, ha dado lugar a numerosas experiencias que intentaron privilegiar las relaciones primarias sobre las secundarias, y se posicionaban críticamente frente al avance de la racionalidad mercantilista. En América Latina, por su lado, ha existido una continuidad histórica, más o menos «contaminada» que viene desde las comunidades indígenas, y que hoy en día nos siguen enseñando cómo es posible organizarse económicamente desde una posición más igualitaria, solidaria y humana.

Finalmente, una tercer lectura que podemos hacer del fenómeno comunitario, y que debemos hacer en el marco del presente trabajo, viene propiamente desde la teología. Cuando se habla de la Iglesia como comunidad, evidentemente la noción macro y micro sociológica, está dejando su lugar a una nueva proposición. Lo comunitario aquí adquiere una connotación más de principio teórico, teológicamente vinculado por un lado, al hecho que todos somos hermanos e hijos del Padre, y por otro lado, al hecho que Dios eligió un Pueblo y no individuos aislados. El Concilio Vaticano II señala en ese sentido que «La vocación humana, en el plan de Dios, tiene un carácter esencialmente comunitario» (GS, 32). En la Conferencia de Medellín por su lado leemos: 
«La Iglesia es ante todo un misterio de comunión católica, pues en el seno de su comunidad visible, por el llamamiento de la Palabra de Dios y por la gracia de sus sacramentos, particularmente de la Eucaristía, todos los hombres pueden participar fraternalmente de la común dignidad de hijos de Dios, y todos también, compartir la responsabilidad y el trabajo para realizar la común misión de dar testimónio del Dios que los salvó y los hizo hermanos en Cristo» ${ }^{14}$.

En el plano propositivo, esta idea de comunidad no ha dado lugar claramente a una línea determinada de acción, sino al menos a tres fenómenos distintos.

a) una primer reacción eclesial, ha sido la práctica de la caridad. Anota Chenu en una reflexión quizá algo generosa:

«Es indiscutible que a lo largo de su historia, la Iglesia ha sido siempre el refugio de los débiles, de los privados de voz, de los pobres. Ella tomó a su cargo las necesidades sociales que los poderes públicos no sabían o no podían subsanar. Educación de los niños, organización de las instituciones de enseñanza, cuidados de los enfermos, alojamiento de los ancianos y, más recientemente, ayuda a los minusválidos, funciones todas ellas que, todavía hoy, en plena civilización industrial, son realizadas por la Iglesia en algunas regiones subdesarrolladas» ${ }^{15}$.

b) Una segunda reacción ha tenido lugär en el plano de la acción pastoral, con el desarrollo de dinámicas de trabajo de tipo «relaciones primarias», que dieron lugar, entre otras experiencias a la constitución de Comunidades de Base, o a considerar las Parroquias como "comunidad de comunidades». En esta línea podemos ubicar también las dinámicas de trabajo de los nuevos movimientos surgidos dentro de la Iglesia en los últimos años, dándole a lo comunitario - acotado a estos términos- una particular preeminencia.

Especial mención merece en América Latina, el hincapié realizado en Medellín y Puebla, de la Pastoral de Conjunto y el rol de las Comunidades de Base. Sin duda fue en la II Conferencia General del Episcopado Latinoamericano en Medellín (1968), donde se dio el primer puntapié:

«La vivencia de la comunión a que ha sido llamado, debe encontrarla el cristiano en su «comunidad de base»: es decir, una comunidad local o ambiental, que corresponda a la realidad de un grupo homogéneo, y que tenga una dimensión tal que permita el trato personal fraterno entre sus miembros. Por consiguiente, el esfuerzo pastoral de la Iglesia debe estar orientado a la transformación de esas comunidades en «familia de Dios", comenzando por hacerse presente en ellas como fermento mediante un núcleo, aunque sea 


\section{Cristianismo y comunidades: La construcción de la utopía}

pequeño, que constituya una comunidad de fe, de esperanza y de caridad. La comunidad cristiana de base es así el primero y fundamental núcleo eclesial, que debe, en su propio nivel, responsabilizarse de la riqueza y expansión de la fe, como también del culto que es su expresión. Ella es, pues, célula inicial de estructuración eclesial, y foco de la evangelización, y actualmente factor primordial de promoción humana y desarrollo» ${ }^{16}$.

c) Una tercer línea, en la que basaremos nuestro análisis en las próximas páginas, tiene que ver con una mayor radicalidad en el uso del término, que nos ubica en la dimensión socioeconómica-solidaria de lo comunitario: nos estamos refiriendo a la constitución de verdaderas comunidades integrales de vida, donde - a la luz de las primeras comunidades cristianas - se comparten las riquezas, se distribuye de acuerdo a las necesidades, se vive físicamente en un mismo lugar, y se practica una espiritualidad en común. De hecho, como veremos enseguida, intentaremos demostrar que han sido numerosas las corrientes dentro del cristianismo a lo largo de la historia, que han logrado articular la visión teológica a la socioeconómica solidaria, fomentando la creación de unidades integrales de carácter comunitario.

\section{Cristianismo, Comunidad y Utopía}

Entre los cristianos, la recurrencia a la vida de comunidades, de acuerdo a esta última noción, se remonta a los tiempos de los primeros apóstoles. En el Libro de los Hechos, se relata la vida comunitaria de los primeros agrupamientos de cristianos, donde se vislumbran algunos de los valores puestos en práctica:

"Todos los creyentes vivían unidos y compartían todo cuanto tenían. Vendian sus bienes y propiedades y se repartían de acuerdo a lo que cada uno de ellos necesitaba. Acudian diariamente al Templo con mucho entusiasmo y con un mismo espiritu y compartían el pan en sus casas, comiendo con alegría y sencillez» (Hech. 2, 44-46).

Más adelanté se anuncian otros elementos:

"La multitud de los fieles tenían un solo corazón y una sola alma. Nadie consideraba como suyo lo que poseía, sino que todo lo tenían en común. Dios confirmaba con su poder el testimonio de los apóstoles respecto de la resurrección del Señor Jesús, y todos ellos vivían algo muy maravilloso. No habia entre ellos ningún necesitado, porque todo los que tenían campos o 
casas las vendían y ponían el dinero a los pies de los apóstoles, quienes repartían a cada uno según sus necesidades» (Hech. 4, 32-36).

Sin duda que estos pasajes son centrales para comprender la organización y desarrollo de posteriores comunidades cristianas, dejando material suficiente para establecer ciertas normas básicas: la residencia unitaria, la comunidad de bienes, el cumplimiento de los ritos religiosos con entusiasmo, el desprendimiento material, el predominio del don y de la redistribución, y un estilo de vida a la vez alegre y austero. Indudablemente estos valores e ingredientes marcarían a fuego los futuros experimentos comunitarios de base religiosa.

Luego de la Paz de Constantino, la vida de comunidades da lugar a la organización eclesial por parroquias, lo que hace de la vida de Iglesia, un estilo más masificado y menos personalizado. El propio crecimiento además, iría de la mano de una mayor acumulación de riquezas, otro rasgo que la diferenciará de la Iglesia primitiva y al que intentarán retornar diversos movimientos. Justamente en el rescate de aquella personalización y vida simple presente en las primeras comunidades, y a la luz de los valores que irradiaban, se empiezan a fundar algunas experiencias comunitarias que tendrán una característica particular: el celibato de sus integrantes. La de mayor alcance en tal sentido, es la establecida por Benito de Nursia (480-547) en los alrededores de la montañosa Subiaco. En su Regla escrita hacia el 527, con la fundación de la abadía de Monte Cassino, San Benito describe las características y normas de la vida monacal. Con respecto a la propiedad señala lo siguiente:

«Por encima de todo, éste vicio debe extirparse del Monasterio: nadie se atreva a dar o recibir cosa alguna sin permiso del abad, ni a poseer nada en propiedad, absolutamente nada... "Que todo sea común a todos", como está escrito, y "nadie diga o considere que algo es suyo" ${ }^{17}$.

Sobre la distribución de los bienes, y en consonancia con los Hechos de los Apóstoles, también señala el Santo:

"Como está escrito, "se distribuirá a cada uno según sus necesidades" ${ }^{18}$

Sobre la división del trabajo señala:

"Los hermanos han de servirse mutuamente, y nadie será dispensado del servicio de la cocina, a no ser por enfermedad, o bien por estar ocupado en alguna cosa muy importante...» ${ }^{19}$. 
$\mathrm{Al}$ igual que en algunas de las más conocidas obras de la literatura utópica, y lo observado en los kibbutzim, parecería ser que el trabajo en la cocina es el menos valorado por el común de la gente, lo que obligó en su momento a San Benito, a señalar la necesidad de que todos pasaran por esta instancia. La obligatoriedad del trabajo menos agradable, es la solución más recurrente. Véase, por ejemplo, cómo Tomás Moro en su Utopía, señalaba que en la isla, el trabajo agrícola era obligatoriamente realizado por cada familia durante dos años. Pero volvamos a la Regla de San Benito: sobre el trato al prójimo valgan dos referencias. Con respecto a los enfermos se señala que

«ante todo y sobre todo ha de cuidarse de los enfermos, de modo que se les sirva como a Cristo en persona...».

Sobre los forasteros, por su lado, explica:

"A todos los forasteros que se presenten, se les acogerá como a Cristo, ya que él un día ha de decir: "era forastero y me acogisteis". $Y$ a todos se les tributará el honor correspondiente, sobre todo a los hermanos en la fe y a los peregrinos» ${ }^{20}$.

Las comunidades monásticas han tenido no solo un gran peso en la conformación cultural de Europa ${ }^{21}$, sino además, y especialmente en lo que respecta a nuestro trabajo, en lo concerniente a proyectos de vida alternativa. No debe llamarnos la atención en ese sentido que por un lado, el citado Moro haya experimentado por algunos años la vida monacal, y que el otro gran utopista del Renacimiento, Tomasso Campanella, en 1582 ingresara como fray Tommaso en el convento de Santo Domingo de Placanica, en Italia. Efectivamente, la vida monacal se puede considerar como un antecedente de las búsquedas de proyectos utópicos y alternativos. La idea de huir de un mundo insoportable, creando una nueva realidad, es algo que tienen en común los utopistas y los monásticos. Por otro lado, como señala el estudio de Frank Manuel, las imágenes monacales se repiten en diferentes utopías, caso de las de los citados autores, o incluso en La Nueva Atlántida de Bacon, etc.

Ahora bien, la vida comunitaria de tipo monacal tiene antecedentes con respecto a la órden religiosa de Benito. En el marco del cristianismo, podemos remontarnos al caso de los eremitas cristianos (de eremos $=$ desierto), constituyendo primero núcleos de ascetas dedicados a la oración en el desierto, y luego comunidades propiamente dichas a las orillas del Mar Rojo. También llamados cenobitas, los iniciados por San Antonio el 
Grande (considerado por muchos el patriarca del monaquismo), derivan su nombre del griego (koinos bios), o sea, vida común. Nótese la evolución de los estilos de vida y de los términos utilizados: de un estilo de vida «solitario» ${ }^{22}$, dedicado a la ascesis y contemplación (de donde se obtiene el nombre de monje, del griego monachos, o sea, solitario), pasamos a una etapa donde se siente la necesidad de la vida en común, lo que da lugar a la vida en conventos de tipo cenobita. Uno de sus discípulos, Pacomio, luego canonizado, fundaba en el año 320 la primera sociedad comunal enclaustrada, en la isla de Tabenna, sobre el Nilo. Con ello instituyó la primer regla monástica que se conserva por escrito (la santa koinonía), rescatándose la prohibición de la propiedad privada, la obligatoriedad del trabajo manual diario y de la oración en común.

A la muerte de Pacomio ya existían nueve cenobios de varones y dos de mujeres, aunque llegaron también a existir conventos mixtos. Estas reglas que podemos catalogar como propias del monaquismo oriental, fueron especialmente divulgadas en occidente entre otros, por San Atanasio en Italia, y San Agustín de Hipona, en el Norte de Africa. Pronto empezarán a conformarse entonces, colonias de varones y mujeres que empezaban a llevar una vida común, de la mano de personajes como San Ambrosio, Rufino, San Jerónimo, San Paulino de Nola y otros ${ }^{23}$. Será recién luego de esta ola primaria de fundaciones de conventos, que San Benito funda los suyos. En el Siglo XI, una nueva ola de fundaciones de comunidades conventuales se vinculará con la actividad y liturgia de los Cartujos (Orden fundada en 1084 por San Bruno) y de los Cistercienses (Orden fundada por San Roberto de Molesmes en el 1098); ésta última con el ánimo de volver a las raíces benedictinas, aparentemente distorsionadas por el gran poder acumulado por parte de los Monjes con el correr de los siglos, producto de su «mundanización» y mayor dependencia con respecto a los Señores Feudales. Este clima será propicio además, como veremos luego, a la proliferación de numerosos colectivos contestatarios, de base laica y popular.

En lo concerniente a la vida monacal en otras culturas, digamos que en la cultura arábica, las comunidades monásticas se remontan al origen del islamismo y a las actividades de los Sufí. En efecto, los Sufí derviches se establecerían sobre todo a partir del Siglo IX, en comunidades monásticas llamadas tekkes o khanagahs.

Más antigua es la tradición hindú por parte de los eremitas quienes se constituían también en comunidades religiosas (ashrams); o el monaquismo budista (sangha), de fundamental importancia en esta religión; o la posterior tradición monástica taoísta, que a diferencia de la budista (y de la cristiana), no exigía el celibato. 
Cristianismo y comunidades: La construcción de la utopía

Pero volvamos al caso de la Iglesia Cristiana. Allí notamos en los primeros siglos de la Edad Media, una serie de cambios socioeconómicos y políticos que afectarían a las instituciones eclesiales y al pensamiento económico de los cristianos. La Edad Media se caracterizaría entre otras cosas, por el incremento del poder secular de los príncipes y su relación de dependencia con las jerarquías eclesiásticas, y por un fenómeno de desmoralización general que también afectaría a la iglesia, sumida en escándalos de simonía y nicolaísmo, y a sus jerarquías, donde no se salvaría la institución papal ${ }^{24}$. Las diferencias empezaban a surgir, y con ellas, emergían movimientos de distinta índole, pero todos con gran participación de los laicos, donde se intentaba rescatar rasgos como el retorno al espíritu de pobreza y fraternidad de la iglesia primitiva, vida en común, literalismo evangélico, denuncia evangélica de las estructuras eclesiales, participación seglar en la gestión eclesial, aspiración a la libertad y responsabilidad, crítica a instituciones vigentes en la Iglesia, etc. ${ }^{25}$ Indudablemente, como señala Chenu, en este marco, también se originaron varias de las consideradas entonces «herejías», entre las cuáles encontramos experiencias muy interesantes en materia económica alternativa, como veremos enseguida.

Vale la pena detenernos en este contexto entonces, para señalar tres grandes tendencias de especial importancia para comprender el desarrollo de una nueva oleada de comunidades religiosas: el surgimiento de movimientos apocalípticos y liberadores; el desarrollo de diversos movimientos de base laica y popular; y el movimiento que podemos llamar monasterial-crítico.

Entre los primeros sin duda alguna. Joaquín de Fiore ha sido el de mayor resonancia. Gran impacto generó su libro Evangelio Eterno, publicado en París hacia el 1254. Allí explicaba que el mundo debía atravesar por tres etapas o estadios: la edad del Padre o de la Ley Antigua, ya terminada; la Edad del Hijo o de la Ley Nueva que inaugura Jesús; y la Edad del Espíritu Santo que comenzaría a operar, según sus cálculos, en el año 1260. En esta tercer edad, reinará el amor y la paz en el mundo, y todos se comportarán como monjes perfectos (Joaquín era monje cisterciense). Joaquín fallece en el año 1202, en un convento calabrés por él fundado. Años después es condenado por el Papa Alejandro IV y declarados sus textos como herejes. Ello no fue obstáculo para que sus seguidores, que los tuvo y muchos, fundamentalmente franciscanos, fueran reconocidos públicamente como espiritualistas. Estos se caracterizaron entre otras cosas, por el desprendimiento material, la vocación por construir una sociedad alternativa, y en algunos casos por la crítica a la jerarquía eclesiástica, lo que les valió la persecución e incluso la ejecución 
de algunos de sus miembros. El joaquinismo, a pesar de todo, cumplió un rol trascendente, entre otras cosas, en el establecimiento de experiencias utópicas (inspiradas en la Edad del Espíritu) en la Iglesia del Nuevo Mundo. También el joaquinismo inspiró movimientos heréticos como el de los Hermanos Apostólicos, que durante el Siglo XIII terminaron tomando las armas para sostener sus reivindicaciones contra la jerarquía eclesial y sus riquezas ${ }^{26}$.

En segundo lugar, debemos hacer referencia al surgimiento de diferentes movimientos laicales de base popular, y de importante contenido social. La llamada «reforma gregoriana» ${ }^{27}$, abriría un nuevo campo de acción a los laicos, tal como fue el espíritu de las primeras comunidades. Entre los movimientos comunitarios que pudieron mantenerse dentro de la Iglesia, y en el marco de una ola de efervescencia por diversas experiencias de vida comunitaria, surgen las órdenes hospitalarias, dirigidas por laicos; una enorme cantidad de confraternidades que todavía hoy siguen teniendo un rol importante en el área del voluntariado en varios países europeos; surge una corriente de laicos y clérigos que rescataban el valor de la pobreza que recibe el nombre de patarinos; el caso de las comunidades de las beguinas en los Países Bajos, que vivían en común sin ser monjas y lograron trascender por sus obras de caridad y amplia cultura; la rama varonil de los begardos; los Hermanos y Hermanas de la Vida Común, fundadores de escuelas populares y casas en común; etc. En todos estos casos, si bien hubo persecución e incomprensión por parte de las jerarquías eclesiales, lograron conservarse pese a todo dentro de la Iglesia ${ }^{28}$. Otro es el caso de movimientos que fueron conformando una teología distinta a la ortodoxa. Entre ellos merece especial atención el movimiento de los Cátaros (del griego, katharos, "puro"). Su acción social contestativa y sus anhelos de perfección cristiana son visibles durante los siglos XI y XII, cuando por ejemplo, los habitantes de Milán, adheridos a esta «herejía» junto a otros cristianos a los que aludíamos recién, recibían peyorativamente el nombre de patarini, por su procedencia de Pataria, una calle de la ciudad muy frecuentada por grupos de vagabundos y menesterosos. Este movimiento de los patarines cobraría cierta importancia en el siglo XI, como movimiento reformista, enfatizando la acción de los laicos enfrentados a la corrupción del clero; aunque en él intervinieron importantes figuras de la jerarquía, caso de quien luego fuera el Papa Alejandro II.

La radicalidad del movimiento, sin embargo, unido a sus dogmas dualistas y maniqueos que nos recuerda al primitivo gnosticismo, generó tendencias claramente anti-eclesiales, lo que llevaría a que la fracción de los albigenses (localizados al Sur de Francia), fuese condenada y perseguida 


\section{Cristianismo y comunidades: La construcción de la utopía}

duramente por la Iglesia luego del Concilio III de Letrán. Sus anhelos de una sociedad e Iglesia diferente, inspirada en la vida apostólica de la Iglesia primitiva, sin embargo, quedarían presentes en la historia, y serían retomados entre otros, por las nuevas órdenes de los mendicantes. Otro antecedente a éstas, sin embargo, es el que se observa por parte del acaudalado Pedro Valdés, quien luego de «convertirse» y distribuir su fortuna, funda junto a otros clérigos de Lyon, el movimiento de los Valdenses, fuertemente inspirado en la espiritualidad de la pobreza, y que contaba entre sus principios, los vinculados al celibato, el ayuno y la propiedad en común. Señala el historiador García Villoslada que «este comerciante lugdunense, puede considerarse como un precursor del Poverello, hijo a su vez de un comerciante de Asís» ${ }^{29}$. El clima de la época, por tanto, conduciría a la concreción de algunas órdenes mendicantes (Franciscanos, Dominicos, Carmelitas y Ermitaños de San Agustín) que pudieron mantenerse al amparo de la Iglesia Católica, a la vez que reivindicaban con su acción comunitaria, un estilo de vida divergente con respecto al que estaba emergiendo en el seno de las diferentes sociedades sobre finales de la larga Edad Media.

En ese sentido, los siglos XII y XIII fueron testigos además, de un tercer movimiento, en este caso de dura crítica a la riqueza y fastuosidad en la que se encontraban los monasterios de la época, incluido Clunny que justamente se erigía en el Siglo IX para recuperar las reglas austeras de tiempo atrás. En ese sentido habíamos ya comentado la fundación de los Cartujos en el 1084 por parte de San Bruno, quien pronto se dedicaría con sus seguidores a una vida de oración, trabajo y penitencia. Dada la extrema rigidez de sus Reglas, se dice que ha sido la única Orden que no ha necesitado reformarse pues nunca se ha deformado. El otro caso es el de la Orden de los Cistercienses, fundada sobre fines del siglo XI por una serie de monjes benedictinos que se retiraron a la soledad del bosque Cîteaux (de allí el nombre) para fundar una nueva abadía con nuevas reglas que pretendían retornar a la primitiva vida de simplicidad y austeridad.

En el Siglo XVI y XVII, sin duda que el pensamiento comunitario dentro del cristianismo se vio reforzado por las literaturas utópicas que emergían del humanismo renacentista. Este género literario justamente surge como reacción a una sociedad más individualista y mercantiliza$\mathrm{da}^{30}$, a la vez que toma como referente el descubrimiento del Nuevo Mundo y las posibilidades de hacer posible con sus habitantes («no contaminados» con ese individualismo que ya reinaba en Europa), el sueño de una sociedad realmente justa que se perfilara como mojón de una etapa histórica cercana a lo que Joaquín de Fiore llamó la Edad del Espíritu 
Santo, que tanta influencia tuviera entre los primeros misioneros en la Iglesia Indiana. Estos estudios utópicos, sin embargo, también generaron sospechas y en algunos casos ciertas posturas fueron tildadas de herejías. Podríamos en ese sentido detenernos en el caso de Campanella, quien precisamente fue uno de los autores acusado de herejía, al sostener diversas instituciones en su Ciudad del Sol, consideradas «anormales» por el establishment de la época. Véase, por ejemplo, cómo este monje dominico, defiende sus tesis de la comunidad de bienes. En efecto, Campanella fue acusado en su momento de hereje, al negar - entre otras cosasque sea justa la propiedad individual de bienes. Campanella, sin embargo, recurre al Papa San Clemente, quien señalara en la Epístola $4^{\mathrm{a}}$ citadas por Graciano en el Can.2, cuestión $1^{\mathrm{a}}$.

"Queridísimos: el uso de todas las cosas que hay en este mundo debía ser común; pero justamente uno se apropió esta cosa; el otro, la de más allá, etc.».

Continúa señalando Campanella, que en el Génesis, Dios no entregó nada en propiedad, sino que todo lo dejó en común.

"Lo mismo dice San Isidoro en el capítulo que trata del derecho natural; y afirma que los Apóstoles y todos los primeros cristianos vivieron de esa forma, como se echa de ver en San Lucas, San Clemente, Tertuliano, San Juan Crisóstomo, San Agustín, San Ambrosio, Filón, Orígenes, y otros. Este género de vida quedó luego limitado únicamente a los clérigos que vivian en comunidad, según atestiguan las personas citadas y además San Jerónimo, Próspero, el Papa Urbano y otros. Pero, hacia el año 470 y bajo el pontificado del Papa Simplicio, éste hizo que la Iglesia estableciera la propiedad de bienes, correspondiendo una parte al Obispo, otra al Templo, otra al Clero y otra a los pobres. Poco tiempo después, el Papa Gelasio y San Agustín se negaron a ordenar a los clérigos si antes no ponían en común todos sus bienes. Más tarde y para evitar la existencia de hipócritas que ocultaban sus bienes, se permitió, aunque no de buen grado, la propiedad individual. Por eso es una herejía condenar la vida en común o decir de ella que va en contra de la naturaleza. Antes al contrario, San Agustín opina que la supresión de la propiedad individual da lugar a un mayor esplendor. Por consiguiente, la comunidad de bienes es preferible, asi en la presente vida como en la futura» ${ }^{31}$.

Continúan en su alegato, citas a San Juan Crisóstomo, San Ambrosio, San Basilio, Santo Tomás, San Clemente, Cayetano, San León Papa, etc.

Esos siglos fueron testigos también de la Reforma y Contra Reforma, y con ellos, como vimos, del surgimiento de numerosos colectivos que impul- 
Cristianismo y comunidades: La construcción de la utopía

saban estilos de vida alternativos. La influencia de los anabaptistas en este campo fue muy importante; y quizá la Guerra de los Campesinos sea el hecho histórico de mayor relieve. Buena parte de los anabaptistas y de los pietistas, sin embargo, deberían emigrar hacia los Estados Unidos, en lo que constituye otro hito en la historia de las comunas de bases religiosas.

En ese sentido, la persecución de algunas sectas durante la Reforma protestante provocó una ola de movimientos emigratorios hacia los Estados Unidos de América. Estas tierras, libres de persecuciones de carácter religioso (al menos de la forma como se estaba desarrollando en Europa), serían testigo del florecimiento de diversas experiencias comunales. Las primeras en establecerse y en expandirse fueron comunas de cuáqueros y amish.

Los Amish son una secta protestante de origen menonita. Entre sus rasgos más llamativos destaca la forma como han mantenido en el tiempo su propio y conservador modo de vida. Su economía se basa en el trabajo agrícola, alejándose de las influencias de la sociedad industrializada de hoy en día.

El nombre de los Amish se lo deben al obispo menonita suizo Jakob Amman, quien en su momento luchó por mantener una estricta disciplina dentro de la Iglesia, so pena de excomunión. Durante el siglo XVIII, los amish fueron víctimas de persecuciones en toda Europa, por lo que se vieron forzados a emigrar a Pensilvania, Estados Unidos. Sus descendientes reciben el nombre de Holandeses de Pensilvania.

La rama amish más conservadora recibe el nombre de Vieja Orden Amish. Se visten de un modo extremadamente sencillo, utilizando corchetes en vez de botones. Viajan en coches tirados por caballos en vez de utilizar vehículos, y todos los hombres adultos llevan barba. Los servicios religiosos se celebran en los hogares; el lavado de los pies se practica unido al servicio de la comunión; como forma de mantener la disciplina, todo aquel que no cumpla con ella es despreciado, y el matrimonio con personas extrañas a la comunidad está absolutamente condenado. Existen también otros grupos amish menos estrictos en cuanto a su disciplina, y están menos distanciados del resto del mundo. Todos comparten las prácticas de creyentes, o adultos, el bautismo y generalmente no toman parte de los asuntos civiles del país, tales como el votar, servir a las fuerzas armadas, y así sucesivamente. Es probable que el número total de miembros, según informa la Enciclopedia Encarta de 1998, no supere los 50.000.

$\mathrm{El}$ otro grupo fuerte ha sido el de los Cuáqueros o Sociedad de los Amigos, que hunde raíces entre los anabaptistas y otros movimientos religiosos laicales como los vistos. Formalmente sus inicios se remontan al año 1647 cuando en torno al predicador inglés George Fox comenzó a di- 
fundirse la doctrina de «Cristo adentro». Desde entonces, sus seguidores se caracterizarán por cumplir al pié de la letra determinados mandatos bíblicos, y por el intento de emular al Cristo en sus hábitos de simplicidad. Integrando comunidades, otras características a destacar son la inexistencia de división sexual del trabajo, y la solidaridad entre sus miembros que más tarde se expandió al resto de la sociedad al punto de recibir en 1947 el Premio Nobel de la Paz por las labores desarrolladas en torno a los comités de Socorro Internacional.

Finalmente, hubo otra serie de experiencias comunales a lo largo de los siglos XVIII y XIX. En 1735, Johann Conrad Beissel funda Efrata, una comunidad pietista en Pensilvania, que sería antecedente de otras comunas pietistas que por su carácter célibe sólo durarán hasta 1786.

En 1774 Ann Lee y sus Shakers (tembladores), ex cuáqueros, comienzan a fundar una serie de comunas en todo el país. Para 1830 ya representaban 30 comunas y 5.000 miembros. Nuevamente el celibato, pero además la muerte de su líder, llevará a una reducción importante a partir de 1875. Los Shakers se han caracterizado, además de por sus danzas, por el especial gusto en la industria del mueble. Llama la atención en el estilo de vida de esta gente, su simplicidad que nos recuerda a los actuales movimientos por una «simplicidad voluntaria» que se multiplican sobre finales de este siglo. En este sentido, es ilustrativa la siguiente canción popular de la época, cantada por sus miembros:

"Tis the gift to be simple, 'tis the gift to be free,

"Tis the gift to be simple, come down where we ought to be,

And when we find ourselves in the place just right,

"Twill be in the valley of love and delight.

When true simplicity is gain'd,

To bow and to bend we shan't be asham'd,

To turn, turn will be our delight

"Till by turning, turning we come round right... ${ }^{32}$

En 1804 George Rapp comienza la fundación junto al resto de los rapistas, de sus «comunidades de igualdad», en Pensilvania. Estas son disueltas en 1905.

En 1819 Joseph Baumler, de origen alemán, funda en Ohio las comunidades de los zoaristas. Entre sus miembros había muchos enfermos y pobres, lo que obligó a un esfuerzo comunitario y solidario que permitiera la supervivencia del grupo. La experiencia durará 80 años, y su disolución ocurrió cuando el enriquecimiento comunal llevó a los miembros a querer una división de bienes. 
En 1841 Humphrey Noyes funda la comunidad de Oneida (hoy importante productora de acero), predicando la tesis teológica perfeccionista. Esta comunidad, sin embargo adquirió notoriedad por la práctica de una comunión total, ya sea de bienes, ya sea de amantes, por la vía de los «matrimonios agrupados». La oposición pública fue muy fuerte y su líder terminó entonces radicándose en Canadá.

En 1842 Christian Metz y sus inspiracionistas fundan aldeas comunales en Buffalo, Nueva York y luego la conocida Amana Society, hoy importante cooperativa agrícola en el estado de Iowa, con alrededor de 1.400 miembros.

La lista de experiencias comunales religiosas que se establecieron en Estados Unidos luego de la Reforma podría ser interminable. Entre ellos, mencionemos finalmente a las hermandades moravia y bohemia, que han seguido teniendo una poderosa influencia en el pensamiento protestante en esta línea; y a los 20.000 hutteranos que todavía hoy se encuentran distribuidos en Norteamérica.

\section{Las Comunidades Cristianas en el siglo XX: economía de comunión y kibbutz cristianos.}

El siglo XX ha contribuído al fortalecimiento de una línea muy diferente a las vistas hasta ahora en materia de comunidades. Desde el ambiente religioso, la generación de comunidades se da en un plano mucho más pastoral que socioeconómico. Aún así, las contribuciones han sido importantes, y merece especial reconocimiento dos fenómenos. En primer lugar, el desarrollo y fortalecimiento de la doctrina social de la Iglesia a partir de la Rerum Novarum de León XIII (1891), que legitimó la acción social de numerosos movimientos católicos que impulsaban un rol más activo de la Iglesia sobre la «cuestión social». En segundo lugar, el Siglo $\mathrm{XX}$ es testigo de otro fenómeno de mucha importancia, como lo es la promoción de los laicos, y de su mano, la constitución de la Acción Católica con sus núcleos especializados en el ámbito estudiantil y obrero. En ese marco, los nuevos aires en la Iglesia se ven plasmados en el Concilio Vaticano II y en la constitución de numerosos movimientos dentro de la Iglesia volviendo a rescatar la importancia de lo comunitario, como ser el caso de los Cursillos de Cristiandad, los Neocatecumenales, las comunidades carismáticas, el Movimiento Familiar Cristiano, Comunión y Liberación, Movimiento de los Focolares, y grupos EAS. Salvo estos últimos dos casos, que veremos enseguida, en el resto, sin embargo, su especial mirada a lo comunitario, no implicaba generar experiencias de carácter 
socioeconómico, sino más bien se apoyaban en lo comunitario para defender una dinámica de trabajo que podría estimular una mejor evangelización. Un paso más allá fue dado, sin embargo, por los grupos EAS y el Movimiento de los Focolares. Estos movimientos, además de basar su dinámica de trabajo en la composición de pequeñas comunidades de oración y evangelización, han sido promotores de experiencias alternativas de hacer economía.

El Movimiento de los Focolares es fundado por Chiara Lubich en Trento, en el año 1943. Actualmente, desde sus oficinas centrales en Roma, Lubich junto a un selecto grupo de mujeres y en menor grado de hombres, dirige con éxito a un movimiento actualmente difundido en 198 naciones, con 2.220.000 adherentes. La espiritualidad, de claras connotaciones ecuménicas, esta compartida entre 50.000 cristianos de distintas denominaciones, entre ellos ortodoxos, anglicanos, luteranos; 30.000 fieles de otras religiones, entre ellos hebreos, musulmanes, budistas, induistas, y 73.000 personas que se declaran no religiosas.

Inspirados en la Doctrina Social de la Iglesia, y meditando la Encíclica Centesimus Annus (1991) el Movimiento da un nuevo paso en el aspecto socioeconómico de su espiritualidad, subrayando el concepto de la comunión de bienes, que venían practicando desde sus orígenes, para dar lugar comenzada la década del noventa, a una serie de ciudadelas donde pudieran operarse y vivenciarse la forma de vida de las primeras comunidades cristianas, practicando de esta manera la economía de comunión.

Si bien la primer ciudadela nace en Italia, la primera en incorporar la noción de economía de comunión surge en las afueras de San Pablo, luego de una visita que realizara a aquella ciudad, la fundadora del Movimiento, Chiara Lubich:

«Pues bien, en estos días nació en la ciudadela Araceli una idea: la de que tal vez Dios llama a nuestro Movimiento en Brasil, donde lo siguen 150 mil personas, a realizar la comunión de bienes, enriquecida por todos los principios de la doctrina social de la Iglesia, pero "globalmente», todo el Movimiento junto. Y pensamos que ese testimonio se podía llevar a la práctica concretamente comenzando por la ciudadela de Araceli ${ }^{33}$.

Esto ha llevado a que el Gobierno brasileño otorgara a Chiara Lubich, la Orden Nacional de la Cruz del Sur, en Octubre de 1997; justamente en momentos que diversas Universidades de dicho país, empezaban a mostrar interés por la economía de comunión.

Los antecedentes de esta «economía de la comunión» que estaba naciendo de forma tan práctica, se remontan a la fundación de la coopera- 


\section{Cristianismo y comunidades: La construcción de la utopía}

tiva «Loppiano Prima», situada en la ciudadela internacional de Loppiano, Italia.

La utopía del Movimiento, al arrancar con la experiencia, que hoy reúne otras catorce ciudadelas en todo el mundo, consistía en recrear una ciudad moderna, con todo lo que la caracteriza, pero donde además se dé testimonio de la espiritualidad focolarina y de la comunidad de bienes. Continúa diciendo Chiara Lubich:

«Nosotros hemos explicitado lo congenial que es a la vida cristiana la comunión de bienes... Si todo el mundo la actuara, no existirían más las desigualdades sociales, los pobres, los que sufren el hambre, los enfermos, los marginados» ${ }^{34}$.

El punto de partida sería Araceli, donde deberían convergir diferentes empresas, expresamente dirigidas y gestionadas de forma eficiente, donde «cada uno tenga la posibilidad de una participación propia»; y donde las utilidades deberían ser puestas en común, de forma que una parte se destine a los necesitados, otra a la «formación de hombres nuevos", y una tercera parte naturalmente para reinversión empresarial. Se daba de esta forma, al decir de Quartana, el primer paso de una comunión de bienes a una economía de comunión. Haciendo uso de nuestros conceptos socioeconómicos solidarios, podríamos decir que los Focolares empezaron a hacer economía alternativa y solidaria en el plano de la distribución (comunión de bienes), para pasar luego al plano de la producción (economía de comunión)con el proyecto de las ciudadelas.

Las comunidades cristianas comprometidas EAS, por su lado, son fundadas en Francia sobre fines de los años cincuenta. La diferencia con respecto a otra serie de movimientos, además de dinámicas de trabajo propias que no vienen al caso analizar, es que la propia constitución de pequeños grupos de trabajo pastoral, llevó a algunos a fundar en 1992, en México, el primer kibbutz cristiano del que se tenga referencia. Dejemos que lo explique uno de sus fundadores, el P. Antonio Hortelano:

«EAS, Comunidades Cristianas Comprometidas, consciente de los graves problemas sociales de nuestro tiempo y de que para solucionarlos no basta ni el cambio de los individuos uno por uno, ni las reformas legislativas desde arriba, sino que es cada vez más necesario hacer experiencias concretas fuertes en plan piloto para formar lideres y ensayar cambios estructurales a nivel humano, se ha decidido a hacer una cadena de comunidades agropecuario-industriales en Iberoamérica y Africa. Y para ello se han inspirado los EAS en el kibbutz judío por ser la experiencia más fuerte y mejor lograda en su estilo...» ${ }^{35}$. 
Hoy el Kibbutz tiene seis hectáreas y media, un área común de tres pisos donde viven sus integrantes y los invitados; zona de invernaderos altamente tecnologizadas, además de árboles frutales y espacio para algunas microempresas. Un dato interesante es que el tiempo de trabajo se distribuye entre lo productivo (recordemos que es una comunidad agro-industrial) y actividades de promoción social entre las poblaciones más desfavorecidas de la zona, lo que hace que el proyecto no sea cerrado como era la característica de las comunidades protestantes del Siglo XIX. Por cierto que al igual que en la experiencia israelí, todos los ingresos se ponen en común y se distribuyen de acuerdo a las necesidades de cada uno, lo que convierte a esta comunidad en una experiencia realmente alternativa en el plano de la distribución.

\section{Concluyendo}

Lo comunitario y lo utópico han ido de la mano a lo largo de la historia del cristianismo. Iluminados por la radicalidad de las primeras comunidades cristianas, a lo largo de todos estos siglos, siempre han existido expresiones del cristianismo tentadas a hacer del Reino de Dios una utopía posible y concreta. Así lo demuestran las notables experiencias de economía alternativa que se fueron tejiendo a su interior, donde los lazos de solidaridad se constituyeron en factores dinamizadores de primer orden: desde las primitivas experiencias de vida cenobítica, pasando por la República de los Guaraníes, hasta llegar a las modernas comunidades cristianas; tenemos ejemplos y modelos que demuestran claramente cómo es posible $h a-$ cer socioeconomía más allá de la lógica individualista, atomizada y racionalista instrumental que caracteriza el modelo de homo oeconomicus que pretende llevar adelante el neoliberalismo.

\section{Notas}

1 El autor es sociólogo y el punto de vista que se usa aquí es el de las ciencias sociales.

2 De hecho, este material multidisciplinario sobre comunidades, producido al comienzo de un nuevo milenio es fiel testigo de tan rica historia.

3 Cfr. Weber, M. Economía y Sociedad, México, FCE, 1969, cap. I, tomo I, p. 32.

4 Lamentablemente WEBER dejó inconcluso su capítulo sobre el mercado en la obra arriba citada. Algunas cosas, sin embargo, son especialmente útiles para nuestro repaso. El mercado a diferencia de las comunidades, por ejemplo, "que siempre suponen confraternización personal, y casi siempre, parentesco de sangre, es, en sus raíces, extraño a toda confraternización». Cfr. Ibidem., p. 494. 


\section{Cristianismo y comunidades: La construcción de la utopía}

5 Cfr. Tönnies, F. Comunidad y Sociedad, Bs. As., Losada, 1947, p. 19.

6 Cfr. Etzioni, A. The Moral Dimension:Toward a New Economics, Nueva York, Free Press, 1988.

7 Cfr. Etzioni, A. La Nueva Regla de Oro, Madrid, Paidós, 1999. Allí, Etzioni en un esfuerzo de síntesis define a la comunidad mediante dos características: "la primera, una oleada de relaciones cargadas de afecto entre un grupo de individuos, relaciones que a menudo se entrecruzan y se refuerzan recíprocamente (antes que meras relaciones de uno a otro o una cadena de relaciones individuales); la segunda, una cuota de compromiso con un conjunto de valores compartidos, normas y significados, así como una historia y una identidad compartidas, esto es, en una palabra, con una cultura".

8 A diferencia de los autores anteriores, a éstos más bien correspondería encasillarlos como filósofos sociales. No obstante ello, creemos que sus nociones de lo comunitario continúan formando parte de esta primer visión que hemos llamado macro social.

9 Cfr. Mounier, E. Manifiesto al Servicio del Personalismo, Madrid, Taurus, 1976, p. 27.

10 Cfr. Mounier, E. Idem. Ant., p. 79.

11 Cfr. Terra, J. P. Mistica, Desarrollo y Revolución, Montevideo, Ed. del Nuevo Mundo, 1969, p. 74.

12 Aunque indudablemente, una sociedad será más comunitaria en la medida en que existan más y mejores experiencias en este campo microsociológico.

13 El relevamiento excluye a los kibbutzim. Aquí lo que se observa es una reducida cantidad de kibbutzim religiosos, y similar comportamiento en materia de perdurabilidad. Para afianzar nuestra tesis, podríamos hacer mención a la experiencia alternativa de mayor perdurabilidad en el tiempo: la «República de los Guaraníes», de base eminentemente religiosa; al igual que las experiencias comunitarias benedictinas, que se remontan al S. VI.

14 Cfr. Medellín, Conclusiones 15,6.

15 Cfr. Chenu, M. D. «La Iglesia de los pobres en el vaticano II», en Gastaldi, I. Síntesis histórica del pensamiento de la iglesia sobre la pobreza y la justicia social, Santiago, Icheh, 1989.

16 Cfr. Medellín, Conclusiones 15,10

17 Cfr. Regla de San Benito, Cap. XXXIII, Santiago, Cal y Canto, 1995.

18 Idem. Ant., Cap. XXXIV

19 Idem. Ant., Cap. XXXV

20 Idem. Ant., Cap. LIII

$21 \mathrm{Al}$ respecto el clásico estudio de Montalembert (notable orador, escritor y político, que junto a Lamennais contribuiría a consolidar el catolicismo social sobre mediados del siglo pasado), Monjes de Occidente, muestra el papel que le cupo a esta orden en la conservación y transmisión de la cultura greco-latina en toda Europa. Recordemos además, los numerosos Papas que salieron de esta Orden: Silvestre II, Gregorio VII, Urbano II, etc., además de filósofos, estadistas y artistas de primer relieve.

22 Estilo de vida que parece haber sido influenciado por San Pablo de Tebas, sobre mediados del Siglo III, quien se retirara al desierto en busca de la paz y tranquilidad necesaria para su re-unión con Dios; seguido luego por muchos discípulos.

23 Cfr. Hernández, F. La iglesia en la historia, Madrid, Col. Síntesis, 1984, Tomo I, p. 136-137.

24 Desde Juan VIII hasta León IX (872-1049) hubo treinta y nueve papas legítimos y cuatro o cinco ilegítimos; varios de ellos fueron elegidos por la fuerza o anticanónicamente; diez de ellos no lograron reinar más de medio año, otros fueron obligados a abdi- 
car, mientras que dos o tres renunciaron a la tiara para volver a exigirla; en tanto siete murieron de muerte violenta. Cfr. Idem. Ant., p. 184.

25 Cfr. Hortelano, A. Comunidades Cristianas, Salamanca, Sígueme, 1987, p. 24-25.

26 GuigneberT, CH. El cristianismo medieval y moderno, México, FCE, 1957.

27 Gregorio VII (1073-1085) como archidiácono había sido inspirador de las reformas iniciadas por Alejandro II, un ex patario que destinó sus esfuerzos a corregir la vida licenciosa de los poderosos y de los clérigos indignos. Gregorio VII continuará en esa línea y será además uno de los precursores de la separación entre Imperio y Pontificado.

28 Para el caso de las beguinas, ya su nombre (al-bigen-sis) sonaba provocativo para la ortodoxia y eso les valió persecuciones. Además, algunas de sus miembros fueron acusadas de tomar contacto con los Hermanos del Libre Espíritu, otra herejía panteísta de la época que perseguía la Inquisición. Aún así Juan XXII protegió a aquellas que quisieran continuar con sus tareas caritativas y comunitarias, siempre que se mostraran claramente ortodoxas. Un buen relato de la labor de estas mujeres puede leerse en EpineyBugard, G. y Zum Brunn, E. Mujeres trovadoras de Dios. Una tradición silenciada de la Europa Medieval, Barcelona, Paidós, 1998.

29 Cfr. Hernández, F. Op. Cit., p. 180.

30 Inspirados en Moro, por ejemplo, y en medio de la Guerra Civil de 1642 en Inglaterra, tuvo lugar la experiencia de los liderados por Gerrard Winstanley, quienes bajo el nombre de los Diggers (cavadores), impulsaron reformas sociales y la práctica de la vida comunal. Finalmente son disueltos en 1650 por los terratenientes.

31 Cfr. Campanella, T. "Cuestiones sobre la República ideal», en Utopías del Renacimiento, Op. Cit., p. 212-113.

32 Cfr. Tower SARgent, L. «Dreams and Other Products of Nineteenth-Century Communities», The Fellowship for Intentional Community, USA, 1996.

33 Cfr. Entrevista a ChIARA LuBICH, en Quartana, P. Et alt. Economía de Comunión. Propuestas y reflexiones para una "cultura del dar», Bs. As., Ciudad Nueva, 1992, p. 12.

34 Cfr. Quartana, P. «Un programa: Economía de Comunión», en Idem. Ant., p. 23.

35 Cfr. Hortelano, A. «Kibbutz Cristiano EAS», mimeo, s/f.

\section{Bibliografía}

Campanella, T. “Cuestiones sobre la República ideal», en Utopías del Renacimiento. México. FCE. 1980.

EPINEY-BugARd, G. y Zum BRunn, E. Mujeres trovadoras de Dios. Una tradición silenciada de la Europa Medieval. Barcelona. Paidós. 1998.

Etzioni, A. The Moral Dimension:Toward a New Economics. Nueva York. Free Press. 1988.

Etzioni, A. La Nueva Regla de Oro. Madrid. Paidós. 1999.

García, M. Regla de San Benito. Santiago. Ed. Cal y Canto. 1995.

GASTALDI, I. Síntesis histórica del pensamiento de la iglesia sobre la pobreza y la justicia social. Santiago. Icheh. 1989.

GuigneBert, Ch. El cristianismo medieval y moderno. México. FCE. 1957.

Hernández, F. La iglesia en la historia. Madrid. Col. Síntesis. 1984. Tomo I.

Hortelano, A. Comunidades Cristianas. Salamanca. Sígueme. 1987.

Hortelano, A. «Kibbutz Cristiano EAS». mimeo. s/f.

Mounier, E. Manifiesto al Servicio del Personalismo. Madrid. Taurus. 1976. 


\section{Cristianismo y comunidades: La construcción de la utopía}

Quartana, P. Et alt. Economía de Comunión. Propuestas y reflexiones para una "cultura del dar». Bs. As.. Ciudad Nueva. 1992.

Terra, J. P. Mística. Desarrollo y Revolución. Montevideo. Ed. del Nuevo Mundo. 1969. TönNIES, F. Comunidad y Sociedad. Bs. As.. Losada. 1947.

Tower Sargent, L. "Dreams and Other Products of Nineteenth-Century Communities". The Fellowship for Intentional Community. USA. 1996.

Weber, M. Economía y Sociedad. México. FCE. 1969. 